\title{
The Influence of "Internet +" of the Current Era
}

\author{
Yu Xiang \\ Qujing normal college, yunnan qujing 655001
}

\author{
Keywords: Internet plus effect; Computer; Network
}

\begin{abstract}
Throughout the history of human development, every technological change has a great impact on our production and life. The Internet occupies the core position in the new technological innovation, and its development will inevitably have a huge impact on our life. The "Internet plus" is a new form of Internet development, "Internet plus" Remodeling and development of a new generation of information technology, the era of social economy, politics, culture and life will have a profound impact.

At this stage, the Internet has penetrated into all aspects of human life, it has made a great impact on the way of people's life and work, and with the continuous progress of science and technology, the Internet has changed our life and work demand, "Internet + is new forms of innovation under the Internet 2. "Internet plus" is a concept of the Internet, it will be the Internet and traditional industries or the necessities of life together, merge the two, is a new form to promote the development of the world. China's "Internet plus" concept in the early 2012 mobile Internet Expo, $\mathrm{Yu}$ Yang first proposed the concept of it, not the development of enterprises is put forward combined with the direction of the internet. In 2014, Li Keqiang attended the World Conference on the Internet to highlight the importance of the Internet, in 2015, Ma Huateng submitted to the "Internet plus" driven to promote social and economic development in China, the same year, Premier Li Keqiang formally proposed the "Internet plus" development plan, the development direction of "Internet plus" made summary: cloud computing, big data, modern enterprise, mobile Internet and Internet of things. It can be said that the development of "Internet plus" has become the mainstream of development, will inevitably have a profound impact on modern times. In this paper the author analyses the concept of "Internet plus", and discusses the influence on the developing direction of the social production.
\end{abstract}

\section{"Internet plus" Concept}

"Internet plus" suggests that the Internet and other things together, here is not a simple sum and connect them together, but the mutual integration, the use of the Internet communication platform, integrating the Internet is our traditional industries, the development of new forms of creation. The Internet as the core of the development of information technology, the Internet and industrial, commercial, tourism, financial industry fully integrate into the innovative elements, a fusion upgrade, this is the real Internet plus.

"Internet plus" the biggest feature is the innovation driven, China's current economic development has encountered a bottleneck, in order to get further development, it must be based on the Internet, innovation driven, China's economic reform, the economic growth of our country to find a new way. In addition, the "Internet plus" also has the characteristics of cross-border integration and openness, cross-border integration means that whether it is very broad, from research to production, industry and trade, investment or consumption, can achieve innovation and development, "Internet plus" change our past social structure, culture and structure the economy of the information revolution, China is to achieve the ultimate Internet connection all. Openness is that means "Internet plus" the previous removal of factors restricting innovation, national innovation will even link up all over the world, so that everyone can have the opportunity to realize their own value. 


\section{"Internet plus" to the Contemporary Era.}

"Internet plus" in today's era is mainly manifested in the industrial field, people's livelihood and the field of education, specifically the following points:

"Internet plus" of Industrial Field. "Internet plus" will combine the Internet and industrial system, change the traditional mode of production, industrial production products $\mathrm{R} \& \mathrm{D}$, industrial development direction, first for product development, Internet plus age makes the product innovation, time, feedback period is shortened, "Internet plus" relates to all aspects of the the industrial manufacturing process, the relationship of industrial structure and production organization mode and enterprises and users have a significant impact, specifically in the industrial production to consumers as the center, which is in the Internet + era, the consumer has changed in the past in the passive situation, can only wait for the production of a large number of Communist after the selection of goods, but to make their consumption habits, purchase intention and other information to consumers and industrial production of organic combination of fire The fee is indirectly involved in the industrial production. As an enterprise, it must adjust its business strategy as soon as possible, take the initiative to update their management and organization, to build a platform for users using new information technology, effective communication is that consumers and increase sales, improve their performance. In the mode of production, intelligence has become the main development direction of industrial production. The network information technology as the foundation, the use of modern sensor technology, automation technology, design, manufacturing and intelligent control in the production process, intelligent production factory physical devices connected to the Internet, let the physical equipment capable of preparing "thinking" by software tools such as the ability to calculate, control and self management. Intelligent production will greatly reduce people's labor intensity, and can greatly improve the efficiency of work. In the development of the enterprise, the Internet based network marketing has become the mainstream of the world. Application of large amplitude Internet plus to enhance the speed of development of electronic commerce, through the platform of e-commerce platform, consumers can directly establish direct contact with the manufacturers, increase product quality feedback speed, reduce intermediate channels, reduce the cost.

"Internet plus" the Area of People's Livelihood. Now our life has been inseparable, and "Internet plus" like we usually use Alipay and WeChat in the scan code payment, online taxi, online registration, are "Internet plus" convenience location. "Internet plus" the area of people's livelihood is mainly reflected in the following aspects: one is greatly providing convenience for people's life, in the highly developed information technology today, the development of Internet plus has been involved in the various medical, education, transportation, tourism, finance and other areas, enhance the role of the Internet "the traditional industry is very obvious, which makes people through the Internet and various industries fully connected, especially the popularity of mobile terminals, so that people can through computer and mobile phone whenever and wherever possible to query the information they want, also can buy what they want by sliding fingertips, people can use the Internet to understand big data the latest hot news, their choice of travel route, to see a doctor. The second is the "Internet plus" to increase the speed of cross-border integration, which is the most obvious sign for the emergence of intelligent Home Furnishing and the popularity of smart Home Furnishing industry in the rapid development at the same time, it also brings people a comfortable living environment and a higher quality of life, in the Internet + era, people entered the custom the era of consumption, people can choose their own products without love. Third, "Internet plus" depth all walks of life at the same time also brought great changes to people's way of life, people find more market from Internet plus, the combination of the Internet and health care for people for medical treatment more convenient, the combination of the Internet and make agriculture more rapid development of agriculture, to help farmers to more sales channels. It can be said that Internet plus makes people's life more convenient, more healthy way.

"Internet plus" in the Field of Education. The rapid development of Internet plus technology means that the education of our country is facing a major change, change Internet plus education; education has gradually turned to the wisdom of education. This is an inevitable trend. The first 
stage for students, computer, mobile phone has become an indispensable tool for their study and life, the use of mobile devices on the website to download the learning data, access to information has become a habit, like China's education informatization education transformation has become an inevitable trend. Secondly, "Internet plus" on the students' learning life had a huge impact, in the Internet era, the education of our country gradually speed up the construction of information network, our school has most of the realization of the full coverage of the network, students and teachers at this stage fully digital education environment, have a lot of impact on people's perception and understanding of the world, modern education should also conform to this trend, to the needs of the students have a clear cognition. For the education in terms of the Internet to achieve the sharing of excellent teachers and excellent resources, through the network classroom, courseware, network communication platform, make the knowledge in the country or even the world spread each other, this is undoubtedly magnified the excellent teachers of wisdom, to provide a basis for fair education. For the school, based on the "Internet plus" based networking and big data technology, intelligent management system through the computer network construction of the school, learning and living conditions of school students have clear grasp, to promote the education system of our country scientific and modernization. For society, "Internet plus" to promote the construction of learning society, in this society, everyone can whenever and wherever possible the learning of knowledge, you can also self access to educational resources, the promotion for the whole society are of great help.

\section{References}

[1] Was Chen Ping. Internet plus and innovation [J]. Journal of Xichang College (NATURAL SCIENCE EDITION), 2015, 04:59-62.

[2] Xu Yun. "Internet plus": a new fusion, new opportunities and new engine [J]. Telecommunication technology, 2015, 04:6-9.

[3] Liu Yi. Audience debut: U.S. Internet content production and consumption integration research [D]. East China Normal University, 2012

[4] Zhu Jian. The Internet's positive impact on the construction of socialist democratic politics in China [D]. Nankai University, 2012

[5] Zhu Xiang. Study on the influence of Internet information industry on China's economic growth [D]. Huazhong University of Science and Technology, 2013

[6] Sang Qianqian. New curriculum effect of [J]. type on "Internet plus" occupation education of college, 2015,07:55. (2)

[7] Choi's founding. On the network communication and its impact on society [J]. Guizhou social science, 2007, (12).

[8] Network on the impact of social interaction [J]. Jiangsu Social Sciences, 2006, (02).

[9] Zhang Yue. The impact of the Internet on the traditional way of thinking [J]. Foreign Social Sciences, 2005, (01).

[10]Zhang Qin. On the network to the social development of the impact of [J]. talent of the road, 2008, (09).

[11]Zhou Chenglong. The influence of information network on modern social relations [J]. Journal of Shanxi Normal University (SOCIAL SCIENCE EDITION), 2007, (02) 